Iztok Arčon • Arnold Pastrello • Laura Catalano •

Maria De Nobili • Pierpaolo Cantone · Liviana Leita

\title{
Interaction between Fe-cyanide complex and humic acids
}

Received: 17 January 2006 / Accepted: 14 March 2006

(C) Springer-Verlag 2006

\begin{abstract}
The fate of cyanides in soil is strongly influenced by the formation of Fe cyanides, which can interact with organic and inorganic colloids and precipitate as stable compounds. Scarce information is available on the capacity of humic acids to interact with cyano-complexes and thus affect the leaching and prevent the risk of contamination of watertable. Here we show that interaction between humic acids (HAs) and ferricyanide complex led to a formation of ferricyanide-humo micelles, and that the interaction did not imply changes in the original structure of ferricyanide complex.
\end{abstract}

Keywords Ferricyanide $\cdot$ Humic acids Interaction Voltammetry $\cdot$ UV-Vis $\cdot$ EXAFS

\section{Introduction}

Cyanid is commonly used in several industrial plants, such as mining, metallurgical and photographic industries, in

\author{
A. Pastrello $\cdot$ P. Cantone $\cdot$ L. Leita $(\triangle)$ \\ A.R.C. Agricultural Research Council - Istituto Sperimentale \\ per la Nutrizione delle Piante, \\ Via Trieste 23, \\ 34170 Gorizia, Italy \\ e-mail: liviana.leita@entecra.it \\ Tel.: + 39-0481-522041 \\ Fax: + 39-0481-520208 \\ I. Arčon \\ Nova Gorica Polytechnic, \\ Vipavska 13, \\ 5000 Nova Gorica, Slovenia \\ I. Arčon \\ Jožef Stefan Institute, \\ jamova 39 , \\ 1000 Ljubljana, Slovenia \\ L. Catalano $\cdot$ M. De Nobili \\ Dipartimento di Scienze Agrarie e Ambientali, University of \\ Udine, \\ Via delle Scienze 208, \\ 33100 Udine, Italy
}

coal gasification plants. The soil of these sites often contains large amounts of cyanide, likely iron-cyanides. In addition, iron-cyanides may reach soil through fertilization because of soil amendments produced by re-processing industrial refuses such as purifier wastes originated from scrubbing of raw gas with iron oxides, blast furnace sludge or paper and de-inking sludge. Unintentional input of ironcyanides to the soils also occurs with the snow-melt runoff of road salts used as anticaking agents during the winter season.

Free iron-cyanide complexes are photolabile, and consequently toxic free cyanide $\mathrm{HCN}_{\mathrm{g}}$,aq and $\mathrm{CN}^{-}{ }_{\mathrm{aq}}$ may be released in the environment through ultraviolet and sunlight radiation. The immobilization of cyanides onto the soil components, such as organic and inorganic colloids, may prevent the photodissociation of iron-cyanides, the release of free cyanides into the soil solution and their transport into the groundwater and surface water. The behavior of these hazardous compounds in soil and the interaction with soil inorganic components have been recently investigated by Rennet and Mansfeld (2002), who reported that stable iron-cyanides complexes with both clay minerals and organic matter occurred in soils. Moreover, humic substances change the solubility of pollutants and, in turn, modify their transfer to plants, as shown by Baraud et al. (2005) for cadmium.

However, scarce information is available on the capacity of soil humic acids (HAs) to interact with the cyanocomplexes and thus to affect their leaching from soils and the consequent risk of contamination of watertable. Humic acids (HAs) are natural carbon-rich biopolymers ubiquitous in terrestrial and aquatic environments, whose multiple properties seem to be purpose-built for many life-sustaining functions, from agriculture to industry, environment and biomedicine (Pena-Mendez et al. 2005). No other biopolymers with wide range of properties are so widely distributed in nature. Although the defined structure of HAs is still subject of long-standing and continued research, present knowledge indicates that building block of HAs is a hydrophobic framework of aromatic rings linked by more flexible carbon chains, with alcohol, 
amide, amine, carboxylic, carbonyl, phenolic, hydroxyl, quinone functional groups (Stevenson 1994). Due to the polyfunctionality, together with the zwitterionic character, HAs are one of the powerful chelating agents among natural substances. In fact, one of the most significant properties of humic acids is their ability to interact with xenobiotics to form complexes of different solubility and chemical and biochemical stability. In addition, HAs behave as supramolecules as they are able to polymerize, aggregate, and form micellar structures (Steed and Atwood 2000).

Here, we investigated the interaction between humic acids and ferricyanide complex by using differential pulse stripping (DPS) voltammetry, UV-visible (UV-Vis) spectroscopy, and extended X-ray absorption fine structure (EXAFS) spectrometry.

\section{Experimental}

Isolation of humic acids (HAs)

Humic acids (HAs) were extracted from a sample of air dried Pahokee Peat (1S103H - IHSS standard material), according to procedure proposed by IHSS.

Titration by UV-visible spectroscopy

Spectra of $1 \mathrm{mM} \mathrm{K}_{3}\left[\mathrm{Fe}(\mathrm{CN})_{6}\right]$ without and with HAs were recorded at scan region between 190 and $450 \mathrm{~nm}$ on a Varian Cary UV-visible spectrophotometer equipped with a 1-cm quartz sample cell. Aliquotes of $5 \mu \mathrm{l}$ of HAs solution, corresponding to $60 \mu \mathrm{g}$ of organic carbon (o.c.), were stepwise added to standard ferricyanide solution. Distilled water with HAs' aliquotes were used as blanks. UV-visible spectra were performed in parallel to the amperometric titrations.

Amperometric titration by use of differential pulse stripping voltammetry (DPS)

A three electrode polarographic analyzer (EG\&G Research 364 ) connected to a 303 EG\&G polarographic cell was employed. Measurements were performed at a glassy carbon stationary working electrode with a Pt wire as the counter electrode and a $\mathrm{Ag} / \mathrm{AgCl}$, sat. $\mathrm{KCl}$ as the reference electrode. The electroactive solution was $1 \mathrm{mM} \mathrm{K}_{3}\left[\mathrm{Fe}(\mathrm{CN})_{6}\right]$ at $\mathrm{pH} 7$, containing $0.1 \mathrm{M} \mathrm{NaClO}_{4}$ as supporting electrolyte. Aliquotes of HAs, corresponding to $60 \mu \mathrm{g}$ of organic carbon (o.c.), were stepwise added to ferricyanide solution.

The DPS experimental conditions for amperometric titration were $120 \mathrm{~s}$ deposition time, $30 \mathrm{~s}$ equilibration time, scanning excursion from -0.4 to $+0.3 \mathrm{~V}, 7 \mathrm{mV} / \mathrm{s}$ scan rate, $50 \mathrm{mV}$ pulse height. Because of the polyelectrolytic nature of HAs, interaction of HAs with iron compounds is strongly favored at neutral $\mathrm{pH}$, and interferences at the work electrode surface were controlled and reliability of the analytical response checked on the reversible redox couple quinone-hydroquinone in presence and in absence of HAs, according to Leita et al. (2001).

The quinone-hydroquinone redox system (in absence and in presence of HAs) has been chosen because HAs are known to have quinoid moieties. Results obtained showed that any interference at glassy carbon electrode has been avoided.

Extended X-ray absorption fine structure spectrometry (EXAFS)

Experiments were performed at Hamburger Synchrotronstrahlungslabor (HASYLAB) - Deutsche ElektronenSynchrotron DESY (Hamburg, Germany).

$\mathrm{X}$-ray absorption spectra of the $1 \mathrm{mM} \mathrm{K}{ }_{3} \mathrm{Fe}(\mathrm{CN})_{6}$ solution without and with HAs (3.6 mg of organic carbon) were measured in a transmission mode at the X1.1 beamline set in the energy region of the Fe K-edge $(7112 \mathrm{eV})$, i.e. from $250 \mathrm{eV}$ before the edge to $1000 \mathrm{eV}$ above the edge. A Si(111) fixed-exit double-crystal monochromator was used with $1 \mathrm{eV}$ resolution at $7 \mathrm{keV}$. Harmonics were suppressed by detuning of the second monochromator. The intensity of the monochromatic X-ray beam was measured by three consecutive ionization chambers. The first was filled with 100 mbar of Ar, the second and third with 400 mbar Ar. Equidistant energy steps of $0.5 \mathrm{eV}$ were used in the $\mathrm{Fe} \mathrm{K}$-edge region, and equidistant $k$-steps region $\left(\Delta k \approx 0.03 \AA^{-1}\right)$ were adopted for the EXAFS. Samples were analyzed in a variable-length liquid absorption cells with kapton windows. The optimal total absorption thickness $(\mu \mathrm{d})$ of about 1 above the Fe absorption edge was found with about $0.6 \mathrm{~mm}$ thick sample layer in the cell. An integration time of $2 \mathrm{~s}$ per step was adopted and two repetitions were superimposed to improve signal-to-noise ratio. The energy calibration was established with simultaneous absorption measurements on $7 \mu \mathrm{m}$ thick Fe metal foil placed between the second and the third ionization chamber.

EXAFS analysis was performed with IFEFFIT based programs (Ravel and Newville 2005) using the FEFF6 code (Rehr et al. 1992), in which the photoelectron scattering paths were calculated "ab initio" from the presumed distribution of neighboring atoms around $\mathrm{Fe}$, from the proposed structure of water solution of $\mathrm{K}_{3}\left[\mathrm{Fe}(\mathrm{CN})_{6}\right]$ (Hayakawa et al. 2004).

\section{Results and discussion}

UV-Vis spectra evidenced the interaction between ferricynide and HAs. The UV-visible spectrum of $1 \mathrm{mM}$ $\left[\mathrm{Fe}(\mathrm{CN})_{6}\right]^{3-}$ displayed a maximum absorption band $\left(\lambda_{\max }\right)$ at $202 \mathrm{~nm}$, and three smooth absorption bands at 259 , 301, and $421 \mathrm{~nm}$. As shown in Fig. 1, the normalized adsorbance values of ferricyanide solution, recorded at the four characteristic $\lambda$, decreased after HAs additions. This spectrophotometric behavior indicated that the whole 


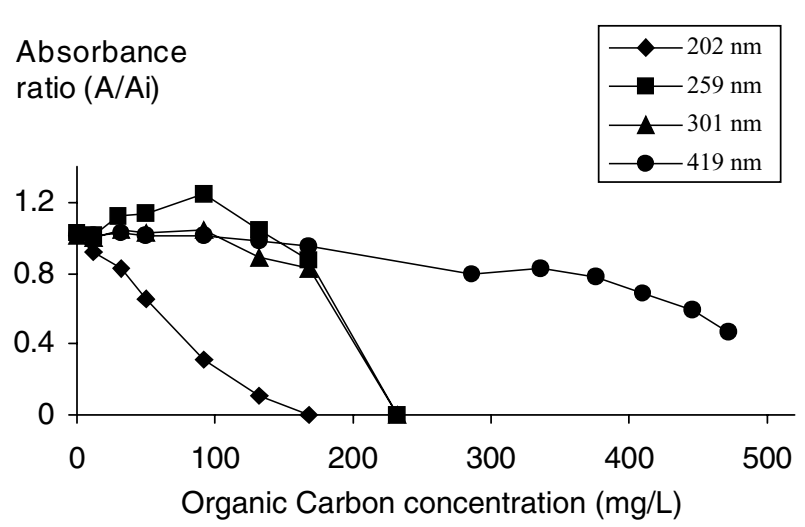

Fig. 1 Normalized absorbance values of $1 \mathrm{mM}\left[\mathrm{Fe}(\mathrm{CN})_{6}\right]^{3-}$ as a function of stepwise additions of HAs $\left(\mathrm{A}=\text { free } \mathrm{Fe}(\mathrm{CN})_{6}\right]^{3-}$, $\mathrm{Ai}$ $\left.\left.=\mathrm{Fe}(\mathrm{CN})_{6}\right]^{3-}+\mathrm{HAs}\right)$, Absorption values are recorded at the four specific $\lambda$ of $\left.\mathrm{Fe}(\mathrm{CN})_{6}\right]^{3-}$

energetic molecular status of ferricyanide molecule was modified by the interaction with HAs. In fact, the observed hypochromic effect might be related to the inhibition of the $\pi-\pi^{*}$ electronic transitions $(202 \mathrm{~nm})$ and the intramolecular charge-transfer $(259,301$ and $419 \mathrm{~nm})$ of ferricyanide as response to the HAs interaction.

The interaction between ferricyanide and standard humic acids was confirmed by voltammetric investigation. Voltammograms recorded on $1 \mathrm{mM}\left[\mathrm{Fe}(\mathrm{CN})_{6}\right]^{3-}$ at $\mathrm{pH}$ 7 showed a well-defined anodic peak current $\left(i_{\mathrm{p}}\right)$ at $+0.160 \mathrm{~V}$ (Fig. 2).

The first addition of HAs, corresponding to $60 \mu \mathrm{g}$ of organic carbon, caused a depression of $i_{\mathrm{p}}$, which progressively decreased after successive additions of HAs (up to $3.5 \mathrm{mg}$ of organic carbon). Afterward, the shape of $\mathrm{I} / \mathrm{V}$ wave and $i_{\mathrm{p}}$ end-value unchanged after supplemental additions of organic carbon. No chemical shift of the peak potential toward negative values was observed throughout the amperometric titration. The voltammetric behavior showed that interaction between ferricyanide and HAs occurred without evidence of formation of definite ferricyanide-humate

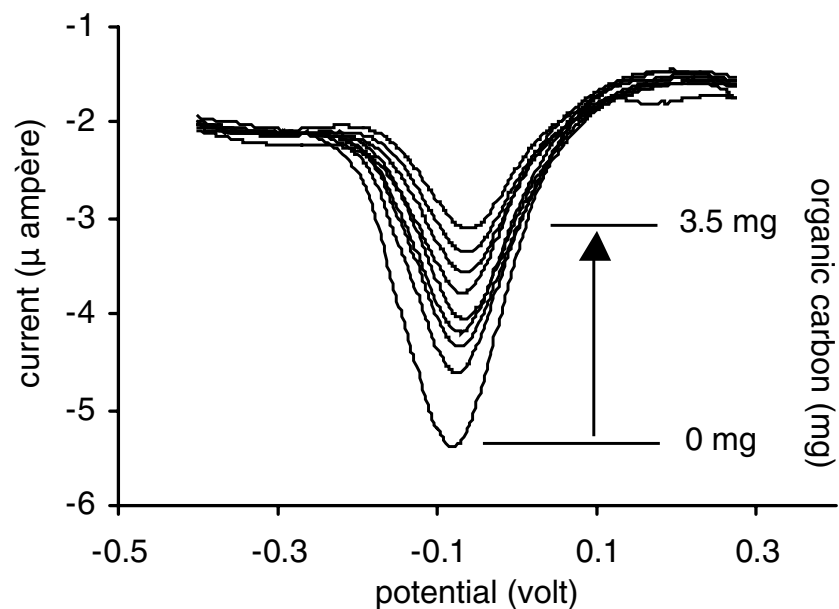

Fig. 2 I/V curves obtained from amperometric titration (differential pulse stripping voltammetry, DPS) of $1 \mathrm{mM} \mathrm{K}_{3}\left[\mathrm{Fe}(\mathrm{CN})_{6}\right]$ before and after stepwise addition of HAs complexes. The clear and progressive depression of the $i_{\mathrm{p}}$ signals, rather suggested the occurrence of a supramolecular process leading to the formation of HAs-ferricyanide micelles that could have been affected the diffusion coefficient of free ferricyanide molecules towards electrodic surface.

To verify whether the interaction between HAs and ferricyanide involved structural modifications on the ferricyanide complex we carried out Fe K-edge EXAFS analyses, which provides information on the local structure around $\mathrm{Fe}$ atoms in the samples. In this method the scattering of a photoelectron, emitted in the process of the X-ray photoeffect, was exploited to scan the immediate atomic neighborhood. EXAFS spectra are normally presented in the Fourier-transform space, where successive shells of neighboring atoms can be distinguished as successive peaks in the transformed spectra. In the quantitative analysis the responses are compared to the EXAFS model function to obtain the coordination number, distance, and Debye-Waller factor of the neighboring shells (Rehr and Albers 2000). Recent Fe K-edge EXAFS analysis of the water solution of $\mathrm{K}_{3} \mathrm{Fe}(\mathrm{CN})_{6}$ showed that the $\mathrm{Fe}$ atom was octahedraly coordinated to six $\mathrm{C}$ atoms at the distance of 1.93-1.94 A. The second coordination shell contained six $\mathrm{N}$ atoms. $\mathrm{Fe}-\mathrm{C}-\mathrm{N}$ angle was almost $180^{\circ}$ and the $\mathrm{C}-\mathrm{N}$ distance $1.15 \AA$ (Hayakawa et al. 2004).

Results obtained on structural modifications of the ferricyanide complex induced by the interaction with HAs could be deduced from the comparison of the measured spectra (Fig. 3). Both EXAFS spectra of $1 \mathrm{mM} \mathrm{K}_{3}\left[\mathrm{Fe}(\mathrm{CN})_{6}\right]$ before and after addition of humic acids were the same within noise level, i.e. no structural changes in the local Fe neighborhood were indicated.

Fourier transform of Fe EXAFS spectra of $\mathrm{K}_{3}\left[\mathrm{Fe}(\mathrm{CN})_{6}\right]$ exhibited two peaks: first originated from single scattering of the photoelectron on $\mathrm{C}$ neighbors, while the second peak was composed of two contributions - single

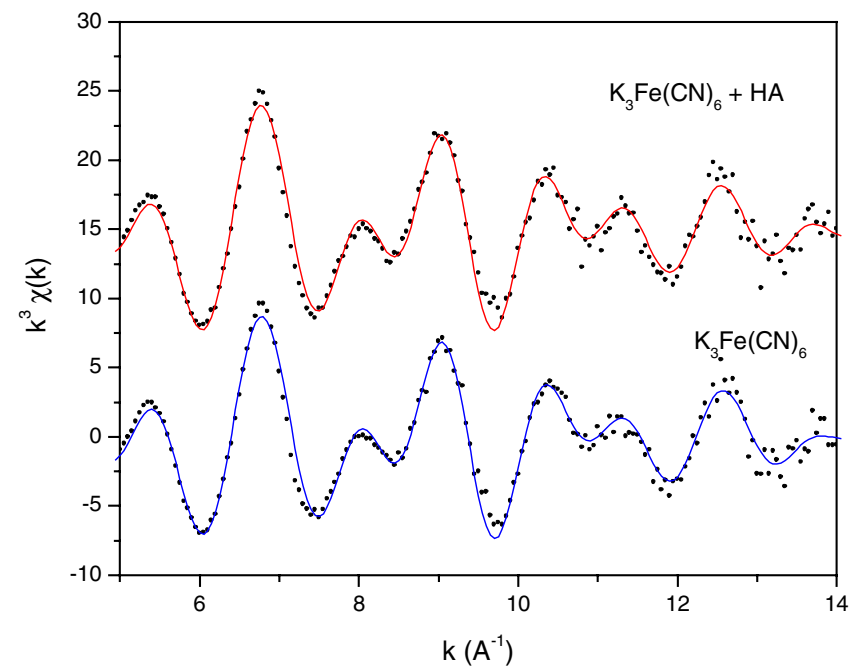

Fig. 3 The $k^{3}$-weighted Fe K-edge EXAFS spectrum of 0.5 molar water solution of $\mathrm{K}_{3}\left[\mathrm{Fe}(\mathrm{CN})_{6}\right]$ before (lower track) and after addition (upper track) of humic acids in the ratio 1:10 
scattering on $\mathrm{N}$ neighbors plus multiple scattering (MS) contribution of $\mathrm{Fe}-\mathrm{C}-\mathrm{N}$ coordination. MS contribution was strong because $\mathrm{Fe}-\mathrm{C}-\mathrm{N}$ atoms were almost aligned, which produced strong focusing effects in photoelectron scattering (Hayakawa et al. 2004).

We constructed the EXAFS model which included all single and significant multiple-scattering paths up to $3.3 \AA$ from the central $\mathrm{Fe}$ atom. A very good agreement between the model and the experimental spectrum was found in the $k$ range of $5-14 \AA^{-1}$, and the $R$ range from 1.3 to $3.3 \AA$ (Fig. 3). The low $k$ part of the EXAFS spectra was not included in the fit to avoid non-structural intra-atomic effects in the atomic absorption background of the Fe EXAFS spectrum at $k<5 \AA^{-1}$ due to multielectron photoexcitations [1s $3 \mathrm{p}]$ and $[1 \mathrm{~s} 3 \mathrm{~s}]$, which cannot be completely described by the standard spline ansatz in the EXAFS background analysis and may introduce systematic errors in the EXAFS analysis (D'Angelo and Benfatto 2004). In addition, we introduced only a minimum number of variable parameters in the model: the amplitude-reduction factor $S_{0}^{2}$, the shift of energy origin $\Delta E_{\mathrm{o}}$, the distance $(R)$ and the Debye-Waller factors $\left(\sigma^{2}\right)$ of $\mathrm{Fe}-\mathrm{C}$ and $\mathrm{Fe}-\mathrm{N}$ neighbors. The shell coordination numbers were fixed during the fit. In case of water solution of ferricyanide, we found six carbon atoms in the first Fe coordination shell at a distance of $1.94 \pm 0.01 \AA$ with a Debye-Waller factor $\sigma=0.004 \pm 0.001 \AA^{2}$, and six nitrogen atoms at a distance of $3.12 \pm 0.04 \AA$ with a Debye-Waller factor $\sigma^{2}=0.003 \pm 0.001 \AA^{2}$. In case of the second sample, where $\mathrm{HA}_{\mathrm{S}}$ was added in the ratio of 1:10 to the water solution of ferricyanide, we found again six carbon atoms in the first $\mathrm{Fe}$ coordination shell at a distance of $1.95 \pm 0.01 \AA$ with $\sigma^{2}=0.005 \pm 0.001 \AA^{2}$, and six nitrogen atoms at a distance of $3.14 \pm 0.04 \AA$ with $\sigma^{2}=0.003 \pm 0.001 \AA^{2}$.

The best-fit values were obtained in both cases with the EXAFS amplitude reduction factor $\left(S_{0}^{2}=0.95 \pm 0.06\right)$ and the $\Delta E_{\mathrm{o}}$ shift $(1.0 \pm 0.5 \mathrm{eV})$ which is, within the experimental errors, in agreement with previous findings (Hayakawa et al. 2004 ).

The structural parameters of the ferricyanide complex before and after the addition of $\mathrm{HA}_{\mathrm{S}}$ are unchanged, and fully agree with previously reported values for ferricyanide complex in water (Hayakawa et al. 2004). The Fe K-edge EXAFS results therefore clearly showed that there are no structural modifications of the ferricyanide complex induced by the interaction with $\mathrm{HA}_{\mathrm{s}}$.

\section{Conclusion}

Results obtained from spectrophotometric and voltammetric analyses indicated that interaction between HAs and the ferricyanide complex probably occurred via a supramolecular process leading to the formation of HAs-ferricyanide micelles. Considering the fact that, according to EXAFS analysis, the interaction did not imply changes in the original structure of ferricyanide complex, this is the only possible hypothesis. This mechanism (Engebreston and von Wandruszka 1994) was hypothesised to explain quenching of pyrene fluorescence by HAs (von Wandruszka 1998).

Acknowledgements The work was supported by the Slovenian Research Agency, the bilateral project BI-DE/03-04-004 by Internationales Buero des BMBF, and the EC- Research Infrastructure Action under the FP6 "Structuring the European Research Area" Programme (through the Integrated Infrastructure Initiative "Integrating Activity on Synchrotron and Free Electron Laser Science"). Access to synchrotron radiation facility of HASYLAB (beamline E4, project II-01-44) is acknowledged. We would like to thank $\mathrm{K}$. Klementiev of HASYLAB for expert advice on beamline operation.

\section{References}

Baraud F, Fan TWM, Higashi RM (2005) Effect of cadmium and humic acids on metal accumulation in plants. In: Lichtfouse E, Schwarzbauer J, Robert D (2005) (eds) Environmental chemistry. Green chemistry and pollutants in ecosystems. Springer, Berlin, pp 205-214

D'Angelo P, Benfatto M (2004) Effect of multielectronic configurations on the EXAFS analysis at the Fe K edge. J Phys Chem A 108(20):4505-4514

Engebreston RR, von Wandruszka R (1994) Micro-organization in dissolved humic acids. Environ Sci Technol 32:448-493

Hayakawa K, Hatada K, D'Angelo P, Della Longa S, Natoli CR, Benfatto M (2004) Full quantitative multiple-scattering analysis of X-ray absorption spectra: application to potassium hexacyanoferrat(II) and- (III) complexes. J Am Chem Soc 126(47):15618-15623

Leita L, Mori A, De Nobili M, Corso G, Franco I, Cenci R (2001) Characterization of ferricyanide-humate complexes by a voltammetric approach. Soil Sediment Contam 10:483-496

Pena-Mendez EM, Havel J, Patocka J (2005) Humic substances compounds of still unknown structure: applications in agriculture, industry, environment, and biomedicine. J Appl Biomed 3:13-24

Ravel B, Newville M (2005) ATHENA, ARTEMIS, HEPHAESTUS: data analysis for X-ray absorption spectroscopy using IFEFFIT. J Synchrotron Rad 12:537-541

Rehr JJ, Albers RC (2000) Theoretical approaches to X-ray absorption fine structure. Rev Mod Phys 72:621-654

Rehr JJ, Albers RC, Zabinsky SI (1992) High-order multiplescattering calculations of X-ray-absorption fine structure. Phys Rev Lett 69:3397-3400

Rennet T, Mansfeld T (2002) Sorption of iron-cyanide complexes in soils. Soil Sci Soc Am J 66:437-444

Steed JW, Atwood JL (2000) Supramolecular chemistry. Wiley, London

Stevenson FJ (1994) Electrochemical and ion-exchange properties of humic substances. In: Humus chemistry, genesis, composition, reactions, 2nd ed. Wiley, London

von Wandruszka R (1998) The micellar model of humic acid: evidence from pyrene fluorescence measurements. Soil Sci 163:921-930 